\title{
GLOBALIZATION AND LOCALIZATION OF HERITAGE PRESERVATION IN TAIWAN - AN ANALYSIS PERSPECTIVE UNDER THE CULTURAL HERITAGE PRESERVATION \\ ACT
}

\author{
CHEN, CHIEN-CHUNG ${ }^{\text {a }}$, FU, CHAO-CHING ${ }^{\text {b }}$
}

a Dept. of Architecture, National Cheng Kung University, Tainan City 701, Taiwan (R.O.C.) - r91544031@ntu.edu.tw

${ }^{b}$ Dept. of Architecture, National Cheng Kung University, Tainan City 701, Taiwan (R.O.C.) - ccfu@mail.ncku.edu.tw

KEY WORDS: Heritage preservation, Cultural heritage, Cultural property, Taiwan, Adaptive reuse, Monument

\begin{abstract}
:
The key contribution to the legislation of heritage preservation in Taiwan primarily derived from the historical monument movements in the 1970s. Specific legislation results include the establishment of Council for Cultural Affairs and the implementation of the Cultural Heritage Preservation Act in 1982. Although the Cultural Heritage Preservation Act is the first subjective cultural act, its lack of structure during the initial commencement stages made it un-conducive to heritage preservation and thus unable to meet the people's expectations. Therefore, throughout the 33 years after the implementation of the Cultural Heritage Preservation Act, the Act has been amended 6 times. These amendments reflect the degree of importance that the society has attached to heritage preservation, and the innovative system also showcases the progress in preservation concepts and methods. These innovative orientations, such as emphasizing on the authenticity and integrity of heritage preservation, intangible cultural heritage, and cultural diversity, conform to the international preservation trends. They are also local trends such as encouraging community participation, adaptive-reuse, or enhancing the local governments' powers to implement local cultural governance. This is particularly true for the fifth comprehensive revision in 2005, which has symbolic significance because its contents epitomized the heritage preservation work while moving Taiwan's heritage preservation system towards globalization and localization. Therefore, we analyzed the Cultural Heritage Preservation Act amendment and revision processes over the past 33 years to highlight the innovations in Taiwan's cultural heritage work and illustrate their globalization and localization features. Finally, we proposed recommendations for Taiwan's preservation work in the future as the Cultural Heritage Preservation Act is about to undergo its seventh amendment in 2015.
\end{abstract}




\section{HISTORICAL MONUMENT PRESERVATION MONUMENTS IN THE 1970s: IMPETUS TO THE LEGALIZATION OF HERITAGE PRESERVATION IN TAIWAN}

In the 1980s, two major events occurred in Taiwan's cultural circles: firstly, the establishment of Council for Cultural Affairs and secondly, the promulgation of the Cultural Heritage Preservation Act. The former marked the first central cultural affairs dedicated ministry for the nation, representing that the country has begun to pay attention to its cultural needs. The latter is Taiwan's first cultural act promulgated to provide the legal authority required to implement the historical monument preservations that were badly needed at the time. However, Taiwan's monument preservation movements in the 1970s are the primary impetus that give rise to the institutionalization of heritage preservation.

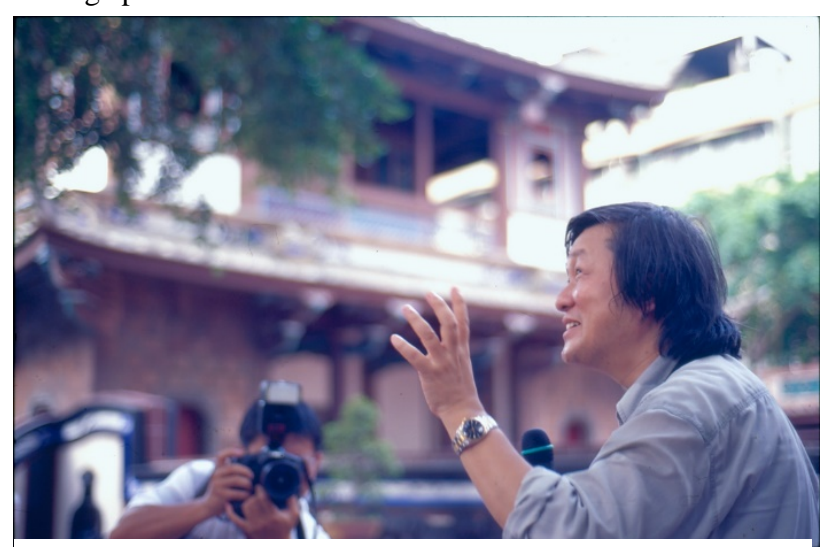

Figure 1: Professor Gan-Lang Li.

Taiwan's historic preser| vation movement was born in the 1970s due to at least two structural factors. The first is the cultural factor. Based on the local cultural identity of the Taiwanese people, historical monument preservation is a specific projection of such cultural identity. The post-war historical monument preservation movements were inspired by a famous historical literature scholar, Heng-Dao Lin (1915-1997), during the early years in the Taiwan province. Heng-Dao Lin was very influential in terms of historical monument preservation and research in Taiwan. He studied in Japan and primarily focused on subjects related to Taiwanese local cultures such as traditional temples, local beliefs, and folk activities. Subsequently, Heng-Dao Lin also influenced some people in the construction industry to start to focus on traditional architecture, and the most representative among them was the work by Professor Bau-De Han (1934-2014) of Tunghai University. Inspired by Heng-Dao Lin and Bau-De Han, Numerous young people have successively followed the movement and joined the traditional architecture investigation and research work in Taiwan. Well known followers include Zhu-Jiu Xia, Kun-Yan Deng, and Gan-Lang Li (Figure 1) et al. Most of these people were born during the post-war baby boomer generation. After graduating from colleges in the 1970s, the conditions provided a young and idealistic support energies needed for the historical monument preservation movements. These intellectuals went on to become a major impetus behind Taiwan's early historic preservation movement. Zhu-Jiu Xia once said, "The waves of criticisms from the intellectuals and cultural elites of the cities constituted the primary force of Taiwan's early monument preservation movements.” The influences of these people enabled the monument preservation topics to gradually become a social concern of the public. Concerns for Taiwan's traditional architectures represented an important source of nonpolitical self-cultural identity for the Taiwanese youths at the time.

The second factor came from the stimulus of rapid urbanization. Zhu-Jiu Xia believes that the destruction of traditional architectures and historical landscapes due to rapid urbanization were the structural conditions that gave birth to the monument preservation movements. After World War II, Taiwan became a part of division of labor for international trades, played the role of original equipment manufacturer (OEM) production base for industries worldwide, and started industrialization and urbanization under the leadership of state capitalism. However, the social costs of rapid economic development have finally produced a wide range of negative effects by the 1970s. In additional to direct environmental pollutions, the uncontrolled urban planning and rapid real estate developments have destroyed numerous traditional architectures and ancient streets, which ultimately resulted in the fragmentation of urban history textures and provoked a social backlash. Heng-Dao Lin once analogized that, "Watching monuments are like watching flowers, they would be gone if you are too slow," and such was the portrayal of Taiwan from the 1970s to the 1980s.

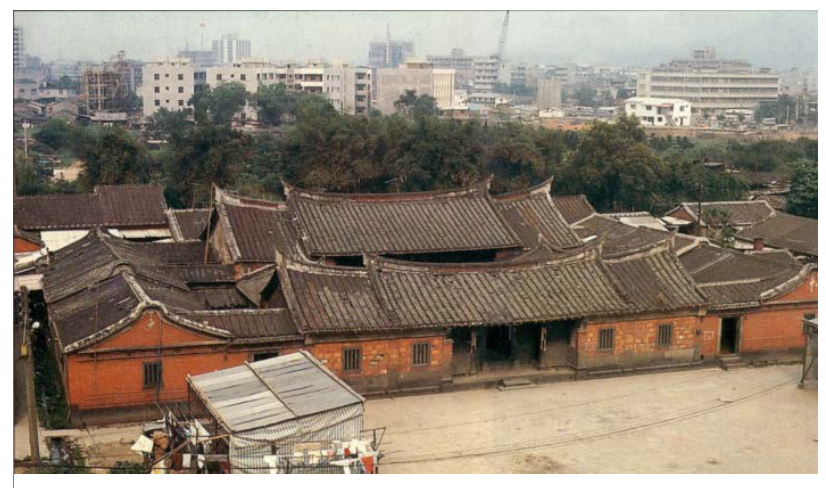

Figure 2: The Lin-An-Tai historic building in 1977 ( Gan-Lang

$$
\text { Li,1977) . }
$$

The Taipei City Lin-An-Tai historical home preservation case in 1976 symbolizes the starting point of monument preservation movements in Taiwan. The Lin-An-Tai’s house (Figure 2) was built in the early Qing dynasty and is one of the few traditional homes that had survived. The preservation controversy started when the city government planned to extend the Dunhua South Road southwards and elected to demolish the old house. (Figure 3) The old house was ultimately demolished on June 26, 1978; and parts of the building was removed and preserved. This is a representative case of post-war monument preservation and urban development conflicts. After the case ended, Yi-Gong Ma assembled the articles by De-Jin Xi, Bao-De Han, and Gan-Lang Li et al. to publish “Goodbye Lin-An-Tai” ( Yi-Gong Ma, 1978) and preserve a little bit of memory for the preservation movement. In short, the monument preservation movements in the 1970s 
provided the driving force for Taiwan to subsequently incorporate heritage preservation into its national cultural policy.

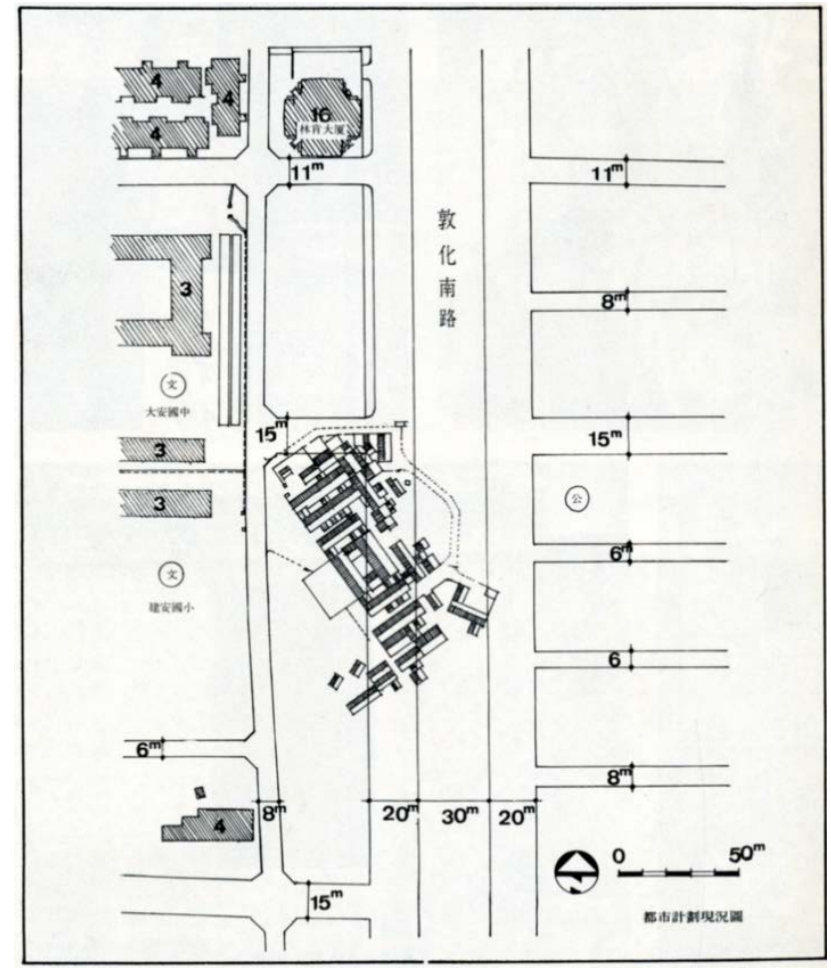

Figure 3: Taipei city government planned to extend the Dunhua

South Road southwards and elected to demolish the old house

(Gan-Lang Li, 1977) .

\section{THE BIRTH OF THE CULTURAL HERITAGE PRESERVATION ACT AND ITS STRUCTURALS SHORTCOMINGS}

\subsection{From construction materials to the era of cultural development}

The Executive Yuan promoted 12 major construction plans in the 1980s, and the twelfth project was cultural construction. In addition to the continued investments in the industrial and transportation constructions, the proposal of cultural construction also reflected that the government has begun to pay attention to the cultural developments of the society. The appearances of the Council for Cultural Affairs and the Cultural Heritage Preservation Act in the 1980s were major achievements for cultural constructions and symbolized Taiwan's official entry into the era of cultural policies. The most important cultural affairs at the time were monument preservations.

\subsection{Taiwan's first post-war cultural act: birth of the Cultural Heritage Preservation Act}

The natural relic preservation method adopted during the Japanese colonial period is the beginning of the first heritage preservation related legalization. After 1949, the national government applied China's "Relics Preservation Act" to Taiwan, but the Act did not function as intended. The Cultural Heritage
Preservation Act promulgated in Taiwan did not enter into force until May 26, 1982. Cultural heritage legislation was promulgated in response to the demands made by the monument preservation events in the 1970 and an attempt to achieve sustainable cultural heritage preservation through the legal system.

\subsection{The structural defects of the Cultural Heritage Preservation Act}

The first edition of the Cultural Heritage Preservation Act had 8 chapters and 61 clauses and over $50 \%$ of its contents were related to relics and monuments, which showcased the central focus of the government at the time. The Cultural Heritage Preservation Act marks the beginning of heritage preservation legislation and demonstrates the importance of heritage to the Taiwanese society. Unfortunately, there were numerous hidden problems at the beginning due to structural defects in the Act itself. The defects and their descriptions are shown in "Table 1.” Therefore, despite the fact that preservation has been legalized since the 1980s, news of monument destructions can still be heard. For example, although the Bei Dou Dian An Temple of Changhua County had been designated as a level 3 monument in 1983, the Ministry of the Interior had to lift its monument status in 1998 and move it to another location for preservation. Therefore, monument preservation requirements made by the cultural circles had to strive to patch out a reasonable system constantly through social protest movements.

Table 1. Structural shortcomings for the first edition of the

Cultural Heritage Preservation Act in 1982

\begin{tabular}{|l|l|}
\hline \multicolumn{1}{|c|}{ Shortcoming } & \multicolumn{1}{|c|}{ Description } \\
\hline $\begin{array}{l}\text { central } \\
\text { competent } \\
\text { authority }\end{array}$ & $\begin{array}{l}\text { Council for Cultural Affairs, Ministry of } \\
\text { the Interior, Ministry of Education, } \\
\text { juncil of Agriculture, etc., had } \\
\text { preservation affairs. Administrative power } \\
\text { was decentralized and made it difficult to } \\
\text { execute government affairs. }\end{array}$ \\
\hline $\begin{array}{l}\text { 2.Misclassificati } \\
\text { on }\end{array}$ & $\begin{array}{l}\text { In terms of cultural relic classifications, } \\
\text { monuments included underground ruins } \\
\text { with different features, but natural cultural } \\
\text { landscapes contained confusing cultural } \\
\text { and natural concepts. }\end{array}$ \\
\hline $\begin{array}{l}\text { 3.Rigid } \\
\text { reservation } \\
\text { method }\end{array}$ & $\begin{array}{l}\text { Monuments restoration must maintain the } \\
\text { original appearances and cannot be } \\
\text { changed. For example, damages must be } \\
\text { restored back to the original colors and } \\
\text { appearances using the traditional } \\
\text { techniques. }\end{array}$ \\
\hline $\begin{array}{l}\text { 5.Lack } \\
\text { reusability } \\
\text { on private } \\
\text { property }\end{array}$ & $\begin{array}{l}\text { Once a private property has been } \\
\text { designated as a monument, its land } \\
\text { development rights are lost. The legal } \\
\text { system had no compensatory measures, } \\
\text { and the Act constituted an infringement on } \\
\text { the private property rights guaranteed } \\
\text { under the Constitution. }\end{array}$ \\
$\begin{array}{l}\text { Monuments had completely lost their } \\
\text { useful functions, which detached }\end{array}$ \\
\hline
\end{tabular}




\begin{tabular}{|l|l|}
\hline & $\begin{array}{l}\text { themselves from the modern society and } \\
\text { the lives of the ordinary people. }\end{array}$ \\
\hline $\begin{array}{l}\text { 6.Lack a reward } \\
\text { system }\end{array}$ & $\begin{array}{l}\text { The Act neither provided any form of } \\
\text { reward nor encouraged citizen } \\
\text { participation. }\end{array}$ \\
\hline $\begin{array}{l}\text { 7.Lack cultural } \\
\text { diversity }\end{array}$ & $\begin{array}{l}\text { That Act emphasized on the Chinese } \\
\text { Culture, did not include aboriginal and } \\
\text { Japanese colonial period cultural } \\
\text { heritages, and cannot accurately reflect the } \\
\text { historical changes in Taiwan. }\end{array}$ \\
\hline $\begin{array}{l}\text { 8.Lack heritage } \\
\text { preservation } \\
\text { education }\end{array}$ & $\begin{array}{l}\text { Cannot combine with school learning or } \\
\text { social education to enhance the } \\
\text { preservation momentum. }\end{array}$ \\
\hline $\begin{array}{l}\text { 9.Authoritarian } \\
\text { preservation }\end{array}$ & $\begin{array}{l}\text { Heritage relic preservation policies were } \\
\text { completely determined by the government } \\
\text { and lacked community participation. }\end{array}$ \\
\hline
\end{tabular}

\section{INNOVATIVE CHANGES IN THE CULTURAL HERITAGE PRESERVATION SYSTEM}

The Cultural Heritage Preservation Act has been amended for a total of 6 times from its promulgation in 1982 to 2011. Each amendment provided innovative heritage preservation concepts and practices. This is especially true for the fifth amendment in 2005, which incorporated common international preservation principles such as emphasizing on the authenticity and integrity of the heritage, adopting modern technologies and materials for repairs, increasing citizen participation, and focusing on the concept of intangible cultural heritage.

\subsection{Innovative preservation system in the 1990s}

\subsubsection{New York City “Transfer Development of Right (TDR)” system and income tax reduction}

In January 1997, the Cultural Heritage Preservation Act was amended for the first time and primarily focused on resolving the private monument equity compensation issues. After "the Luchou Lee family's house” in New Taipei City was designated as a monument in 1985, (Figure 4) the owner cannot engage in land development but must continue to pay housing and land taxes. The Cultural Heritage Preservation Act did not provide a compensation system, and the Act had indeed violated the people's property rights guaranteed under the constitution. Therefore, Taiwan referenced the volume transfer system of New York City to enable private monument owners to use the "Transfer Development of Right (TDR)" method and acquire their original development rights. (Figure 5) Another change was to use the income tax reduction method to encourage general citizens or enterprises to sponsor monument restorations. This move not only helped the government to share the costs of monument reparations, it also pioneered the society's participation in heritage preservation.

\subsubsection{From a centralized to a localized monument designation method}

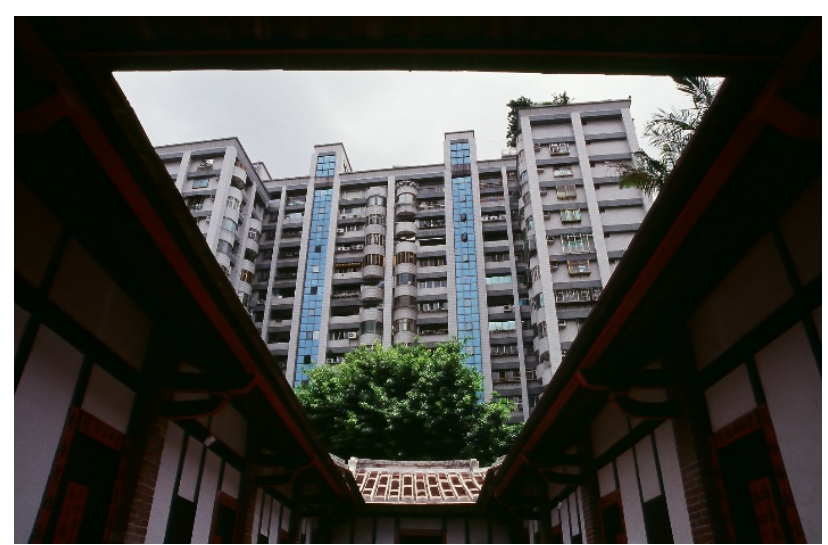

Figure 4: The Lee Family’s House in Luchou District has been a well known historic site in New Taipei City.

In May of the same year, the monument designation review authorities were given back to the local governments, which changed the previous practice where the central government was

responsible to review and designate historical monuments. Since then, various county and city governments have started to designat Japanese colonial buildings as monuments because the law has relaxed, which caused the quantity of monuments to dramatically increase. Furthermore, because the historical value determinations of the monuments have been decentralized locally, the substances of the historical monuments started to resemble more closely the local context. The categories of preservation also no longer focused on the design appearances, the artistic aesthetics of the façade, or long lasting historical values. The questions of monuments can highlight local culture and invoke

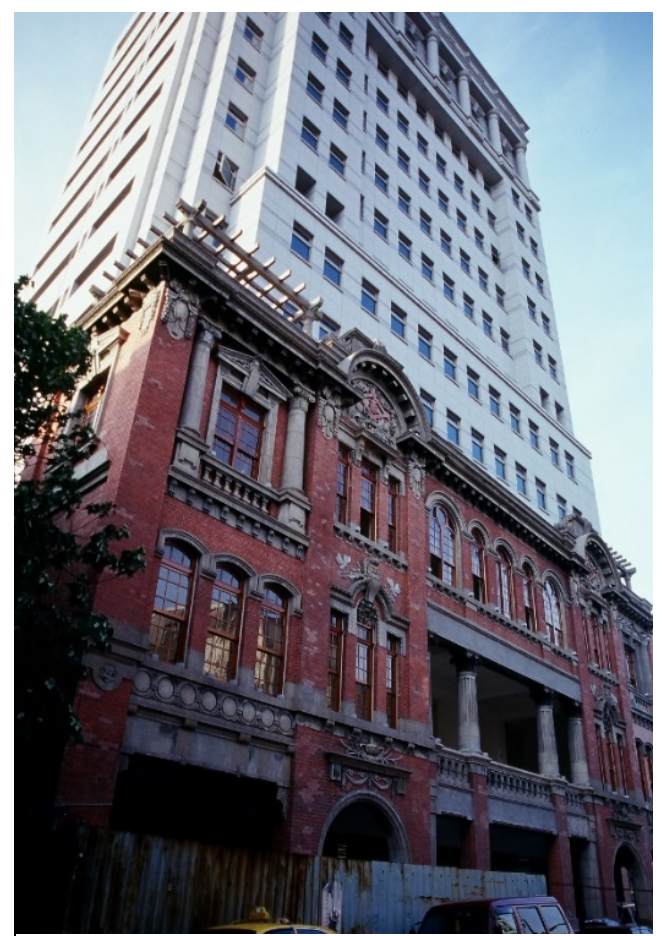

Figure 5: The estate owners can though the TDR to acquire the original development rights. It is a famous case, Ye’s house, at Dadaocheng area in Taipei city. 
recognition by the residents have gradually become the key considerations for preservation.

\subsubsection{Monument adaptive reuse}

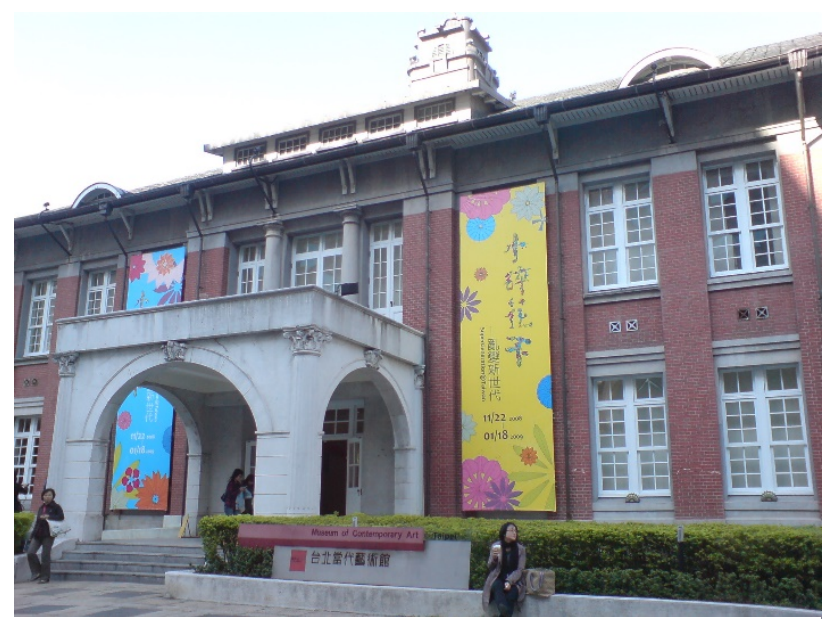

Figure 6: the Taipei City Museum of Contemporary Arts.

As the number of monuments continued to increase, the preservation must further consider how the monument can be returned back to the people's lives. Sustainable development can only be achieved by turning monuments into indispensible parts of modern society like banks, schools, or restaurants. Monuments must also regain their operational energy and value for existence through reuse. Therefore, Cultural Heritage Preservation Act proposed for the first time that monuments may adopt different methods of reuse according to their features. In the 1990s, numerous monuments were turned into museums, exhibition halls, restaurants, or coffee shops as they can be reused and preserved. Examples include the Taipei City Museum of Contemporary Arts (Figure 6), the Taipei Wistaria Teahouse, and the Kaohsiung Museum of History.

\subsubsection{Open new channels of citizen participation}

Taiwan has been a free and democratic society since the 1990s, and public opinion is the core value of democracy. Urban planning permits historic preservation district zoning in order to preserve memorials or buildings that have historic values. Since the land district zoning system affects the interests of the residents, the Cultural Heritage Preservation Act has added new administrative departments in charge of holding briefings or public hearings during the historic site preservation zoning process so that the residents may express their views and have a participation channel.

\subsection{Major changes to Taiwan's Monument Preservation after the 921 earthquake disaster}

On September 21, 1999, a 7.0 Richter scale earthquake caused numerous life casualties and major damages to many monuments in the central southern regions of Taiwan. The Lin family mansion (Figure 7) in Wufeng of Taichung that epitomizes Taiwan's modern history was just about to complete reparation when most of the building toppled during the earthquake. This earthquake was a major test for Taiwan's monument preservation system and exposed numerous existing outdated concepts and implementation errors. To quickly repair the damaged monuments, the Cultural Heritage Preservation Act underwent the most significant amendment in February 2000. Simply put, the focus of the amendment was on the post-disaster monument repair principles and plans in order to incorporate the Venice Charter into the preservation work and integrate with the international experiences.

Prior to 2000, Taiwan's monument preservation principles often contradict those provided by the Athens Charter or Venice Charter. For example, the monument reparation process ignored the "reversibility, identifiability, and non-speculation" principles. The Venice Charter emphasizes that daily maintenance is the most critical work, but Taiwan did not standardize the routine monument maintenance operations. In addition, Taiwan referenced the European experiences and added the "historical building" category as well as the "historical building registration system” in order to prevent historical value buildings from being demolished during a disaster relief processes.

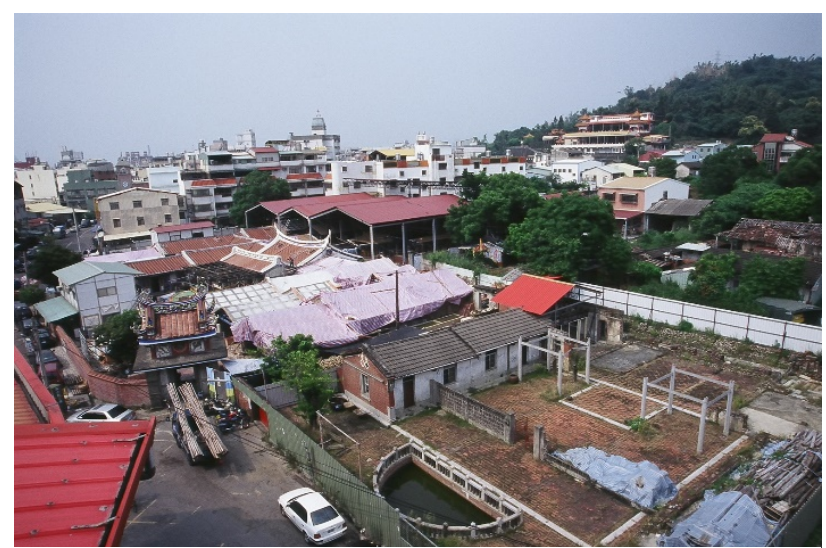

Figure 7: Sept. 21, 1999, most of the historical buildings of Lin

Family in Taichung had toppled during the great earthquake.

\section{GLOBALIZATION AND LOCALIZATION OF HERITAGE PRESERVATION IN TAIWAN}

In February 2005, the new version of the Cultural Heritage Preservation Act was formally implemented, which marked a new milestone for cultural asset preservation in Taiwan. The most prominent features of this amendment was the fact that it has referenced numerous standards provided by critical preservation literatures, such as the 1964 Venice Charter, the 1972 World Heritage Convention, and the 2003 Convention on the Protection of Intangible Cultural Heritage. The preservation operations were also localized to encourage community participation.

\subsection{Heritage classification structure adjustment}

The United Nations Educational, Scientific, and Cultural Organization (UNESCO) has divided world heritages into cultural heritage, natural heritage, and composite heritage. Value boundaries for natural and manmade objects are divided and 
would not mingle with each other. Cultural heritage was further divided into seven categories that comprised memorials, building groups, ruins, cultural landscapes, etc. Taiwan's cultural assets were originally divided into five categories: antiquities, monuments, folk arts, folklore related cultural objects, and natural cultural landscapes. Classification was readjusted into the following 9 categories in 2005 according to their features: monuments, historical buildings, villages, ruins, cultural landscapes, antiquities, traditional arts, folklore related relics, and natural landscapes. ${ }^{1}$ What's special is that culture was divided from natural landscapes so that human intervention can be completely eliminated from natural landscapes, and the cultural landscape item referred to by the World Heritage Convention was added. In addition, ruins were separated from the monuments category. Due to the Japanese colonial influence in the past, Taiwan's heritage classification is more similar to that of Japan. This amendment also cited Japan's “Living National Treasure System" and added "Cultural Heritage Preservation Technicians" in order to nurture the inheritances of intangible cultural skills. $^{2}$

\subsection{Designation and registration parallel system}

The heritage protection methods of nations worldwide can be divided into specification, registration, as well as specification and registration parallel systems. Prior to 2000, Taiwan adopted the specification heritage protection method and the law regulations were more stringent. For example, monument vandalizing can lead to criminal liabilities and penalties. Due to the effects of the 921 earthquake, Taiwan has reference the methods adopted by the European and American countries to newly establish "the historical building registration system" 3 in 2000 in order to provide adequate legal protections to damaged buildings that have preservation value and allow repair operations to become more flexible. Along with the structural amendments in 2005, Taiwan has also adopted the specification and registration parallel system for heritage preservation. In contrast, because registered buildings' preservation value tended to be lower, a greater degree of conversion and reuse is permitted and its legal standards is more lenient compared to that of the specification system while tax incentives are also provided. Another reason that Taiwan has adopted the registration system is to encourage the people to initiate the preservation process. Therefore, no specific penalty is provided.

\subsection{Localized preservation operations and encouragement for community participation}

\footnotetext{
1 Cultural Heritage Preservation Act, Article 3.

2 Cultural Heritage Preservation Act, Article 88: The central competent authority shall review, designate and publicly declare the skills and preservers that are vital to the preservation and restoration of cultural heritage, which are in need of protection.

3 Cultural Heritage Preservation Act, Article 15: Historical Buildings shall be reviewed, registered and publicly declared by the municipal or county (city) competent authority and shall be reported to the central competent authority for recordation. The central competent authority may provide assistances for the
}

Article 2 of the Athens Charter provided that preservation measures must take the local conditions and public opinions into account. In 2007, the World Heritage Convention added another C (Community) in the "4C Strategy" declared in Budapest in order to emphasize the importance of community participation in community involvement. Therefore, if the general public is to discover any buildings worth preservation, the law gives people the right to apply to the local administration department for monument designation review. On the other hand, most fundamental changes in terms of preservation localization are the transfer of the heritage management responsibilities to the local governments so that the Central Ministry of Culture is not directly involved. The advantages are that the local officials can face the citizen directly and listen to their opinions, and the administration can also quickly respond to the actual demands. Another significant change is that the competent authority must reach a census on the tangible or intangible cultural heritage objects that are worth preserving within its jurisdiction and establish relevant information to facilitate subsequent follow-ups.

In particular, a new preservation category - the planar type settlement - was added in 2005. Because numerous occupants live in this type of heritage and it covers a wide range of land, the executive branch would not take the initiative to implement registration logs so as to avoid controversies. On the contrary, the residents of the settlements must reach a consensus first and apply to the local government to implement a preservation review. This is an innovative method for citizen participation in terms of heritage preservation.

\subsection{Monument preservation, restoration, and adaptive reuse}

Prior to 2000, monument restorations in Taiwan rarely referenced international experiences. Their practices were also fraught with dangers because they were not backed by research or wellplanned. The 921 earthquake had directly fast-tracked the monument restoration reforms in Taiwan. Taiwan must face numerous severe monument damages after the earthquake, review the errors of the previous preservation concepts and practices, accept the importance of the international heritage restoration principles, and accelerate the corrections. Therefore, Taiwan has adopted parts of Articles 4 and 10 in the Athens Charter that relevant to modern technology and material principals, applied them to Taiwan's monument restoration operations, and transcended the previous obsolete provisions providing that monuments must retain their original appearances and materials. ${ }^{4}$ In recent years, Taiwan has also gradually implemented the authenticity standards emphasized by the Nara

registered Historical Buildings.

4 Cultural Heritage Preservation Act, Article 21: Monuments shall be preserved in their original appearance and construction method. In the event that a Monument is destroyed or damaged, but its main structure and materials survive, repairs shall be made in accordance with its original appearance. Depending upon its particular characteristics, the owner, user and manager of the said site may submit a proposal to adopt appropriate methods of repair or reuse of the said site upon receiving the approval by the competent authority. The repair plan referred to in the preceding 
Document in 1994 to monument preservations and restorations. In addition, after the 2003 Xi'an Declaration and 2008 Quebec Declaration, the international community believes that the intangible value of tangible cultural heritage can easily be lost due to ignorance, and must receive attention in order to maintain the integrity of heritage value. In recent years, Taiwan has also begun to recognize this holistic preservation concept, which was shown in its preservation efforts for the various military communities and Japanese-style dormitories.

Heritage cannot be disassociated from the society and become abandoned buildings with no relationships to the people's lives. Cultural heritage reuse is the consensus among the international community. The Venice Chapter believes that using monuments for social application purposes would always facilitate the preservation of the monument. Article 1 of Taiwan's Cultural Heritage Preservation Act has been revised to emphasize on preservation and active reuse in response to the international preservation principles. ${ }^{5}$ The Charter for the Interpretation and Presentation of Cultural Heritage Sites in Quebec at the 2008 also agrees that adequate exhibition or interpretation should be used to enhance the public's recognition on heritage preservation. The National Museum of Taiwanese Literature in Tainan City and the Land Bank Museum of Natural History in Taipei are good examples of such monument reuses in Taiwan.

\subsection{Emphasis on the cultural diversity of intangible cultural heritage}

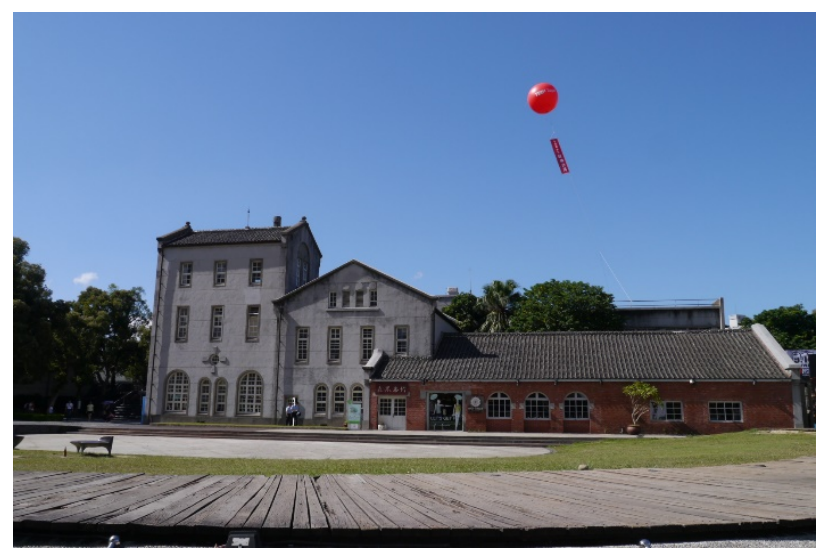

Figure 8: Taipei Huashan 1914 Creative Park.

Maintaining cultural diversity is a universal value, and intangible cultural heritage preservation reflects cultural diversity. The advent of the 2001 Universal Declaration on Cultural Diversity, the 2003 Convention on Intangible Cultural Heritage, and the 2005 Convention on Cultural Diversity demonstrated the importance of intangible culture heritage to the international community. Since 2005, Taiwan's heritage preservation policy has followed the international trends, and Article 1 of the Cultural

paragraph may include, if necessary, modern technologies and construction methods in order to enhance the Monument's resistance to earthquake, natural disasters, flood, termite and its durability. The reuse plan as referred to in the first paragraph, may, if necessary, include proposal to add other necessary facilities, but the original appearance of the Monument should not be
Heritage Preservation Act showcased the "multiculturalism promotion" legislative spirit of heritage preservation for our country. In recent years, the various counties and cities have reflected the importance of intangible culture heritage based on the registration quantities for traditional arts and folk activities. There are presently close to 400 cases for the two categories, which illustrate the rich cultural diversity in Taiwan.

\subsection{Emerging Heritage under the globalization perspective}

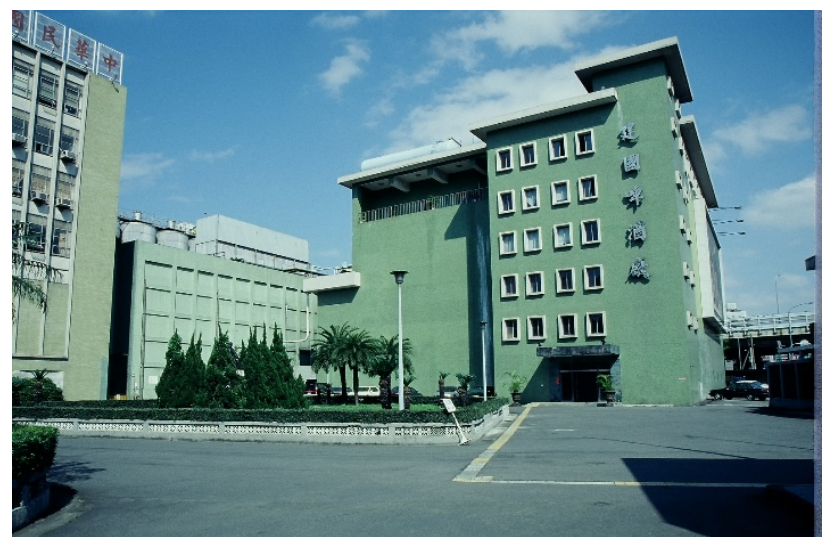

Figure 9: Taipei Jianguo Brewery was the first beer factory in

Taiwan history, as known as a famous industrial heritage.

New international preservation ideas such as industrial heritage, underwater cultural heritage, cultural landscapes, and modern architecture have a significant impact to Taiwan's cultural assets preservation policy. In 2012, the 14th International Committee for the Conservation of the Industrial Heritage (TICCIH) was moved to Asia and held in Taipei for the first time. The Taipei Declaration for Asian Industrial Heritage after the conference has accelerated the pace for industrial heritage preservation in Taiwan. The scope of industrial heritage is large and often conflicts with land developments and arouses controversies. In Taipei, the Taipei Railway Workshop, Huashan 1914 Creative Park (Figure 8), Songshan Cultural and Creative Park, and Taipei Jianguo Brewery (Figure 9) are examples of such cases that urgently needs a solution strategy. In 2001, the United Nations Educational, Scientific, and Cultural Organization (UNESCO) passed the Convention on the Protection of Underwater Cultural Heritage. Taiwan has followed the international footsteps and formulated the Underwater Cultural Heritage Protection Bill in 2009. In addition, the Ministry of Culture and the French Department of Archaeological, Underwater, and Submarine Research (DRASSM) have signed Taiwan and French underwater archaeology cooperation agreements in 2007 and 2012. Taiwan anticipates referencing the experiences of France to improve its preservation capacities for underwater cultural assets. After numerous years of efforts, Taiwan was finally able to join Docomomo International as a member in 2014. This move

affected.

${ }^{5}$ Cultural Heritage Preservation Act, Article 1: The purpose of this Act is to preserve and enhance cultural heritage, enrich the spiritual life of the citizenry, and promote the multi-cultural environment of the Republic of China. 


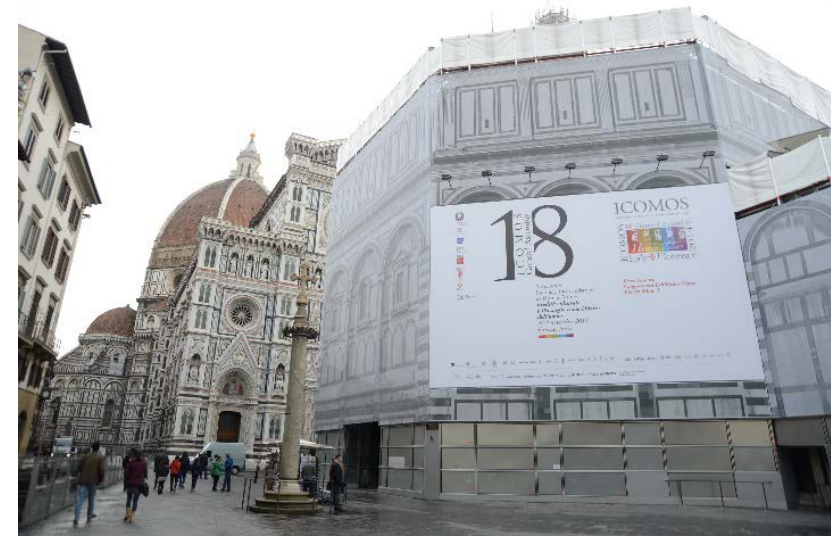

Figure 11: 2014 Declaration of Florence indicated that heritages

has the power to drive urban redevelopment.

not only increased the visibilities of Taiwan's international heritage preservation organizations, it also opened up the modern post-World War II architectural heritage preservation topics as well. Monuments in Taipei, such as the Chiang Kai-shek Memorial Hall, Yangmingshan Zhongshan House, and the Mosque are subjects that the Docomomo International is currently committed to preserve. On March 30, 2015, Taiwan and AusHeritage have signed the Memorandum of Understanding (MOU) on cultural heritage cooperation to work together on cultural initiatives such as underwater archeology and preservation techniques.

\section{CONCLUSION}

Taiwan's heritage preservation efforts in recent years are reflected by its amendments to the Cultural Heritage Preservation Act as well as its endeavors to develop cultural policies and organize heritage promoting events. Examples include the Potential World Heritage Sites in Taiwan that commenced in 2002 and the Intangible Cultural Heritage Potential Sites
Promotional Program in Taiwan that started 2010. The former currently has 18 cases (Figure 10) and the latter has 12 cases. These cases can improve the people's concepts and general attitudes towards heritage preservation, and assess potential cases in Taiwan that may have world heritage registration value. It is hopeful for Taiwan to transcend the political interferences from China and become a member state to the World Heritage Convention. In addition, Taiwan has imitated France's World Monuments Day and held national heritage visiting events on the third weekend of each September since 2001.

At present, the Cultural Heritage Preservation Act is undergoing the seventh amendment. While there were numerous systematic innovations in the past, there are still some long-term problems that have not yet been resolved. These problems include that the capacity transfer system should avoid deviating from compensation intents, the improper use of the cultural landscape registration system, and the lack of attractive incentives. Moreover, Taiwan currently has over 800 monuments, and how to convert burdens into assets is a tough problem for urban development. However, the 2011 Declaration of Paris and the 2014 Declaration of Florence (Figure 11) both indicated that heritages as a driver to promote urban redevelopment. Therefore, Taiwan should abandon its development myth of blindly pursuing urban hardware constructions in the past, and turn to develop the potential value of heritage and create a sustainable urban development governance policy at the cultural governance level

\section{REFERENCES}

Bureau of Cultural Heritage ( BCH ) , 2010. Introduction to Potential World Heritage Sites in Taiwan. BCH, Taichung, p.11. Gan-Lang Li, 1977. The offerings of historical conservation movement: the Lin-An-Tai house. Taiwan Architect Magazine, (4), pp. 33-35.

Yi-Gong Ma, 1978. Goodbye Lin-An-Tai. Crown, Taipe.

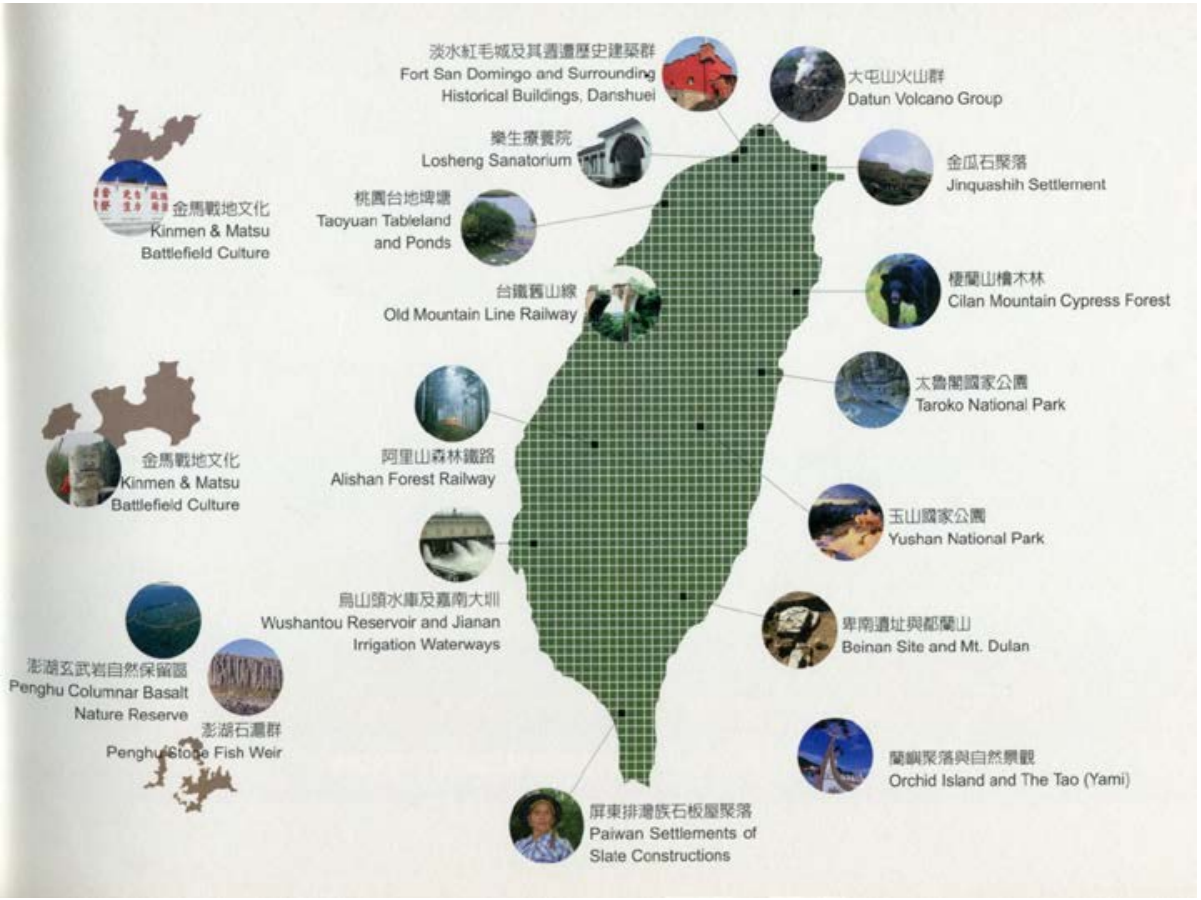

Figure 10: The Taiwan 18 Potential World Heritage Sites Plan. 